\title{
Acquisition of pig intramuscular preadipocytes through dedifferentiation of mature adipocytes and establishment of optimal induction conditions
}

\author{
W. Sun ${ }^{1}$, H. Wang ${ }^{1,2}$, Y. Li ${ }^{1}$, X. Zhou ${ }^{1}$, Y. Teng ${ }^{1}$ and J. Chen ${ }^{1}$ \\ ${ }^{1}$ College of Animal Science and Technology, Nanjing Agricultural University, \\ Nanjing, Jiangsu, China \\ ${ }^{2}$ Hangzhou Academy of Agricultural Sciences, Hangzhou, Zhejiang, China \\ Corresponding author: J. Chen \\ Email: jiechen@njau.edu.cn
}

Genet. Mol. Res. 12 (4): 5926-5936 (2013)

Received August 23, 2012

Accepted March 22, 2013

Published November 26, 2013

DOI http://dx.doi.org/10.4238/2013.November.26.2

\begin{abstract}
Intramuscular fat deposition is a major contributing factor to variations in pork quality. Understanding the mechanisms driving the differentiation and metabolism of muscle-derived adipocytes is important for regulating the fat deposition in muscle. Studies on intramuscular adipocytes commonly involve stromal-vascular (SV) cell cultures, which contain preadipocytes but also several other types of primordial cells. Hence, it is crucial to obtain pure intramuscular preadipocytes for investigating adipocyte differentiation and metabolism in muscle tissue. In this study, we established cultures of pure intramuscular preadipocytes that were derived from mature adipocytes of newborn pigs. Pure mature adipocytes were isolated from the longissimus dorsi (LD) muscle and allowed to dedifferentiate into fibroblast-like cells in ceiling culture. These fibroblast-like cells turned out to be preadipocytes; they exhibited the ability to redifferentiate into mature adipocytes when adipogenically induced in vitro. The redifferentiation process was confirmed by lipid accumulation
\end{abstract}


in the cytoplasm and expression patterns of peroxisome proliferatoractivated receptor gamma 2 (PPAR $\gamma 2$ ), CCAAT/enhancer binding protein alpha $(\mathrm{C} / \mathrm{EBP} \alpha)$, lipoprotein lipase (LPL), and adiponectin genes, which were all similar to those observed in previous preadipocyte studies. We optimized the induction conditions for intramuscular preadipocytes by adding $0.25 \mathrm{nM}$ dexamethasone (DEX), $5 \mu \mathrm{g} / \mathrm{mL}$ insulin (INS), and 0.1 mM 3-isobutyl-1-methylxanthine (IBMX). Therefore, this study provides a new model for studying the mechanisms of intramuscular preadipocyte differentiation and metabolism.

Key words: Mature adipocytes; Intramuscular preadipocytes; Dedifferentiation; Redifferentiation; Induction conditions

\section{INTRODUCTION}

Deposition of intramuscular fat (IMF) can substantially impact muscle sensory quality and meat palatability (Fernandez et al., 1999; Fortin et al., 2005; Lonergan et al., 2007). Pork containing 2.5-3.5\% IMF depots are known for their high palatability (DeVol DL, 1988). However, over the last few decades, the average pork IMF content has decreased significantly below this level due to the intensive selection for lean meat content (Gerbens et al., 1998). The production of pig meat with favorable IMF content remains a challenge in modern pig breeding practices. The main difficulty in ameliorating pork quality results from the negative genetic correlation between IMF content and body fat content. However, intramuscular fat can be distinguished from other fat depots based on its unique pattern of metabolism. Hence, knowledge about the differential regulation between fat depots is of particular importance in order for animal scientists to control fat deposit effectively (Webb and O'Neill, 2008; Hausman et al., 2009).

Research related to the mechanisms of adipogenesis commonly employ lines or cultures of stormal-vascular (SV) cells (Fernyhough et al., 2005). These cell lines, 3T3L1 and 3T3-F442A, are generally derived from murine cells (Wolins et al., 2006) and do not always reflect adipocyte differentiation in other species (Sanosaka et al., 2008). Many studies of pig adipogenesis depend on the origin of SV cells. Although SV cells can accurately reflect the physiological processes of an organism, they also contain other cell types, such as fibroblasts, endothelial cells, monocytes, and pericytes, which may affect the differentiation of preadipocytes (Ramsay et al., 1992). Therefore, it is important to investigate intramuscular adipogenesis in order to obtain pure muscle-derived preadipocytes.

In a culture flask completely filled with medium, mature adipocytes can adhere to the top surface of the flask by buoyancy (Sugihara et al., 1986); a method referred to as "ceiling culture". The mature adipocytes can dedifferentiate into pure and proliferativecompetent progeny cell populations (Fernyhough et al., 2004) that possess characteristics of redifferentiation into adipocytes in cattle (Fernyhough et al., 2008). This is an ideal model for the study of adipocyte metabolism as these progeny cells are exclusively derived from adipocytes. Therefore, the objective of this study was to obtain intramuscular preadipocyte cells via dedifferentiation of mature adipocytes derived from the longissimus dorsi muscle of newborn pigs using the ceiling culture method. Furthermore, optimal conditions for inducing intramuscular preadipocytes were also investigated. 


\section{MATERIALS AND METHODS}

\section{Cell isolation}

Mature intramuscular adipocytes were isolated from the LD muscle of newborn pigs following methods outlined in Fernyhough et al., (2004) with some modifications. Three day-old female Landrace/Duroc pigs were obtained from a local nursery and were killed by exsanguination. The experiment adhered to guidelines outlined in "The Instructive Notions with Respect to Caring for Laboratory Animals", issued by the Ministry of Science and Technology of the People's Republic of China. The LD muscle was washed with phosphate-buffered saline (PBS, Gibco, Grand Island, NY, USA) containing 1\% Penicillin-streptomycin (Pen/Strep, Gibco). The LD muscle was minced into approximately $1 \mathrm{~mm}^{3}$ slices in Dulbecco's modified Eagle's medium (DMEM, Gibco), supplemented with $1 \%$ Pen/Strep, and then digested in 3 volumes of sterile enzyme solution which contained $0.1 \%(\mathrm{w} / \mathrm{v})$ Type I collagenase (Gibco) and $1.5 \%$ bovine serum albumin (BSA, Sigma, St Louis, MO, USA) in DMEM. The tube was incubated for $1 \mathrm{~h}$ at $37^{\circ} \mathrm{C}$ with gentle shaking. After digestion, the cell suspension was filtrated through a $300 \mu \mathrm{m}$ screen cloth to remove undigested tissue debris and then centrifuged at $190 \mathrm{~g}$ for $10 \mathrm{~min}$. The supernatant containing mature adipocytes was aspirated to a new centrifuge tube with DMEM and then centrifuged at $190 \mathrm{x} g$ for $10 \mathrm{~min}$. The steps above were repeated twice in order to obtain pure mature adipocytes in the top layer of the tube.

\section{Cell culture}

The fatty layer was transferred to a $25 \mathrm{~cm}^{2}$ cell culture flask, which was completely filled with DMEM $+10 \%$ fetal bovine serum (FBS), inverted in order to allow the floating mature intramuscular adipocytes to adhere to the top inner surface of the flask, and incubated in a $37^{\circ} \mathrm{C}$ incubator with $5 \% \mathrm{CO}_{2}$ and $95 \% \mathrm{O}_{2}$. After a 12 - $\mathrm{h}$ incubation period, the cell media were transferred to new flasks, which were again entirely filled with DMEM $+10 \%$ FBS. This purification step was repeated twice in order to remove contaminant fibroblasts and obtain pure mature intramuscular adipocytes. Six days later, excess cell culture media was removed and the culture flask was turned right side up. The medium was changed every 3 days until confluence was achieved.

\section{Growth curve}

Dedifferentiated progeny cells $\left(5 \times 10^{3}\right)$ were placed in the wells of 96-well plates. The culture medium was first changed one day after incubation and then every 2 days following. Cell numbers were measured using the 3-(4,5-Dimethylthiazol-2-yl)-2,5-diphenyltetrazolium bromide (MTT) method every 2 days. A $50 \mu \mathrm{l}$ MTT solution was added to each well and incubated for $4 \mathrm{~h}$ at $37^{\circ} \mathrm{C}$. The fluid was then discarded and $150 \mu \mathrm{l}$ dimethyl sulfoxide solution (Sigma) was added to each well. The fluid was then shaken for $10 \mathrm{~min}$ to enhance dissolution and absorbance was measured at $550 \mathrm{~nm}$. At each time point, empty wells without cells were used as blank controls. Seven replicates $(\mathrm{N}=7)$ were established for each group at each time point.

\section{Real-time reverse transcription-polymerase chain reaction (RT-PCR) analysis}

Total RNA was extracted from dedifferentiated progeny cells with TRIzol (Invitrogen, 
Carlsbad, CA, USA) reagent, according to manufacturer protocols. The purity and concentration of RNA were checked on a NanoDrop1000 Spectrophotometer (Thermo, USA). Total RNA (500 ng) was reverse-transcribed using a reverse transcription kit (Takara, Dalian, China), according to manufacturer instructions. Expression levels were analyzed by RT-PCR for four lipogenic genes: PPAR $\gamma 2, \mathrm{C} / \mathrm{EBP} \alpha, \mathrm{LPL}$, and adiponectin. The invariant control used was $\beta$-actin. The primer sequences are listed in Table 1. The RT-PCR was performed in a total volume of $20 \mu \mathrm{L}$, containing 10 $\mu \mathrm{L} 2 \mathrm{X}$ SYBR Premix Ex Taq (Takara), $0.4 \mu \mathrm{L}$ 50X ROX reference dye (Takara), $0.4 \mu \mathrm{L}$ forward primer $(10 \mu \mathrm{M}), 0.4 \mu \mathrm{L}$ reverse primer $(10 \mu \mathrm{M}), 2.0 \mu \mathrm{L}$ template, and $6.8 \mu \mathrm{L}$ sterile water. RT-PCR was performed in the ABI PRISM 7300 Fast Real-Time PCR system and reaction conditions were as follows: $95^{\circ} \mathrm{C}$ for $30 \mathrm{~s} ; 40$ cycles of $95^{\circ} \mathrm{C}$ for $5 \mathrm{~s}, 60^{\circ} \mathrm{C}$ for $34 \mathrm{~s} ; 95^{\circ} \mathrm{C}$ for $15 \mathrm{~s}, 60^{\circ} \mathrm{C}$ for $1 \mathrm{~min}$, $95^{\circ} \mathrm{C}$ for $15 \mathrm{~s}$. Relative mRNA expression levels were analyzed using the $2^{-\Delta \Delta C \mathrm{CT}}$ method.

\begin{tabular}{|c|c|c|}
\hline Accession No. & Gene name & Primer sequence: $5^{\prime}-3^{\prime}$ \\
\hline$\overline{\mathrm{AF} 103946}$ & $\operatorname{PPAR} \gamma 2$ & $\begin{array}{l}\text { Sense: TGTTATGGGTGAAACTCTGGGAG } \\
\text { Antisense: GAAATGTTTGCAGACAGCGTG }\end{array}$ \\
\hline XM_003127015 & $\mathrm{C} / \mathrm{EBP} \alpha$ & $\begin{array}{l}\text { Sense: AGACAAGAACAGCAACGAGT } \\
\text { Antisense: AGACAAGAACAGCAACGAGT }\end{array}$ \\
\hline NM_214286 & LPL & $\begin{array}{l}\text { Sense: CCCGACGACGCAGATTTT } \\
\text { Antisense: GGATGGCTTCTCCAATGTTA }\end{array}$ \\
\hline NM_214370 & Adiponectin & $\begin{array}{l}\text { Sense: GCTGTACTACTTCTCCTTCCACATCA } \\
\text { Antisense: CTGGTACTGGTCGTAGGTGAAGAGT }\end{array}$ \\
\hline DQ845171 & $\beta$-actin & $\begin{array}{l}\text { Sense: TGCTGTCCCTGTACGCCTCTG } \\
\text { Antisense: ATGTCCCGCACGATCTCCC }\end{array}$ \\
\hline
\end{tabular}

\section{Determination of lipid content}

The cellular lipid content was determined by oil red $\mathrm{O}$ staining. Cells were washed 3 times with PBS, and then fixed with $10 \%$ formalin for $15 \mathrm{~min}$. After fixation, the cells were washed with PBS 3 times more and stained with oil red O for $20 \mathrm{~min}$. Subsequently, the cells were washed with $60 \%$ isopropanol for $20 \mathrm{~s}$, and then the solution was discarded and dried. To extract the oil red, $300 \mu \mathrm{L} 60 \%$ isopropanol was added to one pore of the 12-well culture plate and then incubated for $1 \mathrm{~h}$ at room temperature. After extraction, the absorbance values of the solutions were measured at $510 \mathrm{~nm}$. The cultures were then washed with water 3 times and digested with $0.25 \%$ trypsin (Gibco) for $24 \mathrm{~h}$ at $37^{\circ} \mathrm{C}$. The solutions were then centrifuged at $12,000 \mathrm{~g}$ for $30 \mathrm{~s}$. Finally, the digestions were measured at $260 \mathrm{~nm}$, which reflects the number of cells in the well. The oil red $\mathrm{O}$ absorbance values were standardized by absorbance at $260 \mathrm{~nm}$.

\section{Induction of dedifferentiated intramuscular adipocytes}

Two days after the progeny cells reached confluence, the growth media was changed to differentiation media supplemented with 0.02-12.5 mM DEX (Sigma), 0.004-2.5 mM IBMX (Sigma), and 0.04-25 mg/mL INS (Sigma,) in 10\% FBS + DMEM (Table 2). The cells were cultured in the differentiation medium for 3 days, and then replaced with 10\% FBS + DMEM growth medium for 6 days. The medium was changed every 3 days.

\section{Statistical analysis}

All data are presented as means \pm SE. The average change in mRNA levels $(\mathrm{N}=3)$ before 
and after the differentiation stimuli and the difference in lipid content between the 3rd and 9th passages $(\mathrm{N}=4)$ were compared with the independent Student $t$-tests (SPSS Inc., Chicago, IL, USA). The effects of different concentrations of DEX, IBMX, and INS on lipid content were assessed by one-way analysis of variance (SPSS). $\mathrm{P}<0.05$ was considered to be statistically significant.

Table 2. Inducing conditions for progeny cells redifferentiation.

\begin{tabular}{ll}
\hline Groups & Concentration gradient \\
\hline DEX $(\mu \mathrm{M})$ & $0 ; 0.02 ; 0.1 ; 0.5 ; 2.5 ; 12.5$ \\
$(5 \mu \mathrm{g} / \mathrm{mL}$ INS, $0.5 \mathrm{mM} \mathrm{IBMX)}$ & $0 ; 0.04 ; 0.2 ; 1 ; 5 ; 25$ \\
INS $(\mu \mathrm{g} / \mathrm{mL})$ \\
$(2.5 \mu \mathrm{M}$ DEX, $0.5 \mathrm{mM}$ IBMX) & $0 ; 0.004 ; 0.02 ; 0.1 ; 0.5 ; 2.5$ \\
IBMX (mM) & \\
$(2.5 \mu \mathrm{M}$ DEX, $5 \mu \mathrm{g} / \mathrm{mL}$ INS) & \\
\hline
\end{tabular}

\section{RESULTS}

\section{Isolation and dedifferentiation of mature adipocytes}

Mature adipocytes were lipid-laden and of low density, which allowed them to float to the top layer of the culture and attach to the inner ceiling surface of the flask. We used this ceiling-culture method to isolate intramuscular mature adipocytes from the LD muscle. After purification, we obtained pure mature intramuscular adipocytes (Figure 1A) without contamination of fibroblast-like cells. The mature adipocytes began to adhere and to extend their cytoplasm (Figure 1A) at $12 \mathrm{~h}$ after placement. During the ceiling culture process, the mature adipocytes phenotypically changed into fibroblast-like cells whose cytoplasm contained less lipid droplets. Fibroblast-like progeny cells were observed surrounding adipocytes at day 4 (Figure 1B), and increased substantially by day 6 (Figure 1C). By day 10, mature adipocytes had dedifferentiated completely into fibroblast-like progeny cells (Figure 1D).

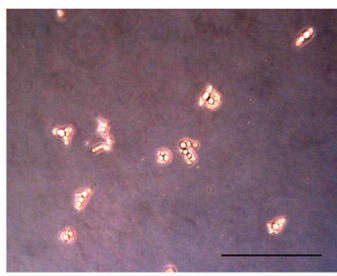

A

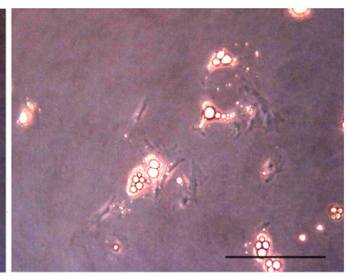

B

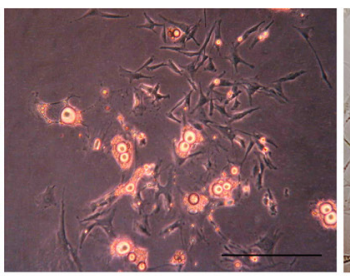

$\mathrm{C}$

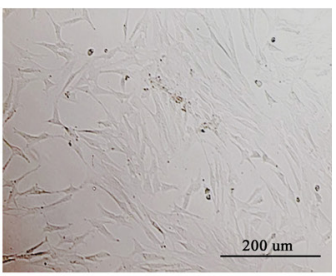

$\mathrm{D}$

Figure 1. Morphological changes in the dedifferentiation process of intramuscular mature adipocytes. A. Morphology of adipocytes on $12 \mathrm{~h}$ of culture. B. Morphological of adipocytes at the 4th day of culture. C. Morphological of adipocytes at the 6th day of culture. D. Morphological of adipocytes at the 10th day of culture.

\section{Growth and redifferentiation of dedifferentiated intramuscular adipocytes}

The growth curve of progeny cells is shown in Figure 2A. The number of progeny cells increased rapidly from the 2nd day to the 10th day, and achieved saturation by the 10th day. The progeny cells were induced to differentiate by differentiation media supplemented with $10 \% \mathrm{FBS}, 2.5$ 
$\mu \mathrm{m}$ DEX, $5 \mu \mathrm{g} / \mathrm{mL}$ INS, and $0.1 \mathrm{mM}$ IBMX 2 days after reaching confluence. The characteristics of progeny cell redifferentiation were reflected by changes in morphology (Figure 2B) and expression levels of adipogenic genes (Figure 2C). The fibroblast-like appearance of progeny cells did not change until adipogenic induction (Figure 2B.a). On the 3rd day, cells containing tiny lipid droplets were observed in fibroblast-like preadipocytes (Figure 2B.b). On the 9th day, more cells containing lipid droplets were observed in the cytoplasm (Figure 2B.c), and both the size and number of lipid droplets had increased. During the redifferentiation process, the expression levels of PPAR $\gamma 2, \mathrm{C} / \mathrm{EBP} \alpha, \mathrm{LPL}$, and adiponectin were analyzed by RT-PCR before and after adipogenic induction (Figure 2C). All gene expressions were significantly increased after adipogenic induction on the 9 th day $(\mathrm{P}<0.01)$.

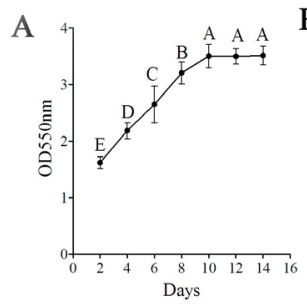

C

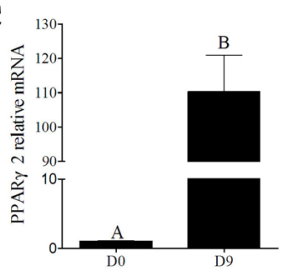

a
B

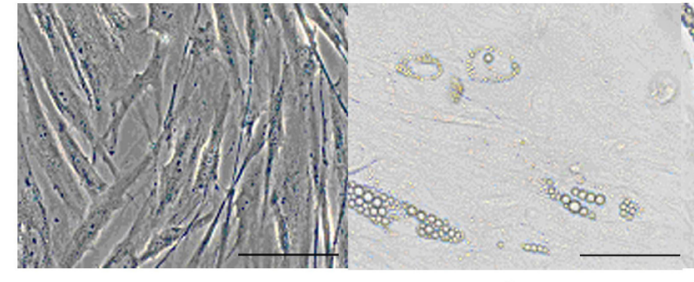

a

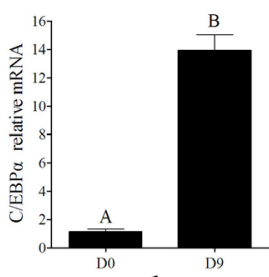

b b

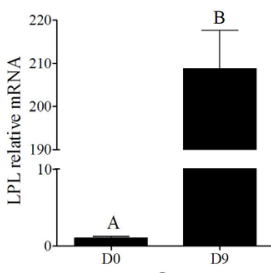

c

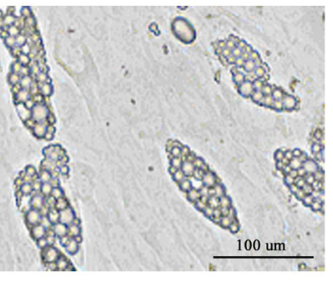

c

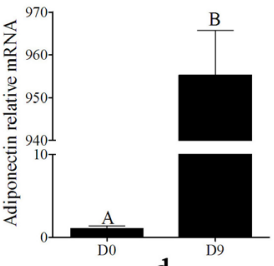

d

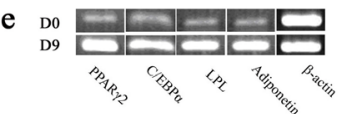

Figure 2. Characteristics of dedifferentiation intramuscular adipocytes. A. Growth curve of progeny cells after culture. B. Morphological changes in the redifferentiation process of dedifferentiation intramuscular adipocytes. $\mathrm{a}=$ Morphology of progeny cells before induction. $\mathrm{b}=$ Morphology of progeny cells at the 3rd day of induction. $\mathrm{c}=$ Morphology of progeny cells at the 9th day of induction. C. Gene expression levels of adipogenic markers during redifferentiation process of progeny cells (D0 sample was obtained at 0 day before induction, D9 sample was obtained at the 9th day after induction). $\mathrm{a}=\operatorname{PPAR} \gamma 2$ relative mRNA abundance before and after induction. $\mathrm{b}$ $=\mathrm{C} / \mathrm{EBP} \alpha$ relative $\mathrm{mRNA}$ abundance before and after induction. $\mathrm{c}=$ LPL relative mRNA abundance before and after induction. d: Adiponectin relative mRNA abundance before and after induction. $\mathrm{e}=$ Electrophoresis picture of RT-PCR products. Averages with different letters are significantly different $(\mathrm{P}<0.01)$.

\section{Influence of DEX, INS, and IBMX on progeny cell redifferentiation and comparison of redifferentiation in different passages of dedifferentiated intramuscular adipocytes}

In order to obtain optimal induction efficiency, different concentrations of DEX, INS, and IBMX were used to induce redifferentiation in the dedifferentiated intramuscular adipocytes using 3rd passage progeny cells. Lipid accumulation exhibited dose dependence of DEX, INS, and IBMX at the 9th day after lipogenic induction (Figure 3). Lipid accumulation 
in the progeny cells was highest at the 9th day of induction after the addition of $2.5 \mu \mathrm{M}$ DEX, $5 \mu \mathrm{g} / \mathrm{mL}$ INS, and $0.1 \mathrm{mM} \mathrm{IBMX}$, respectively (Figure 3).
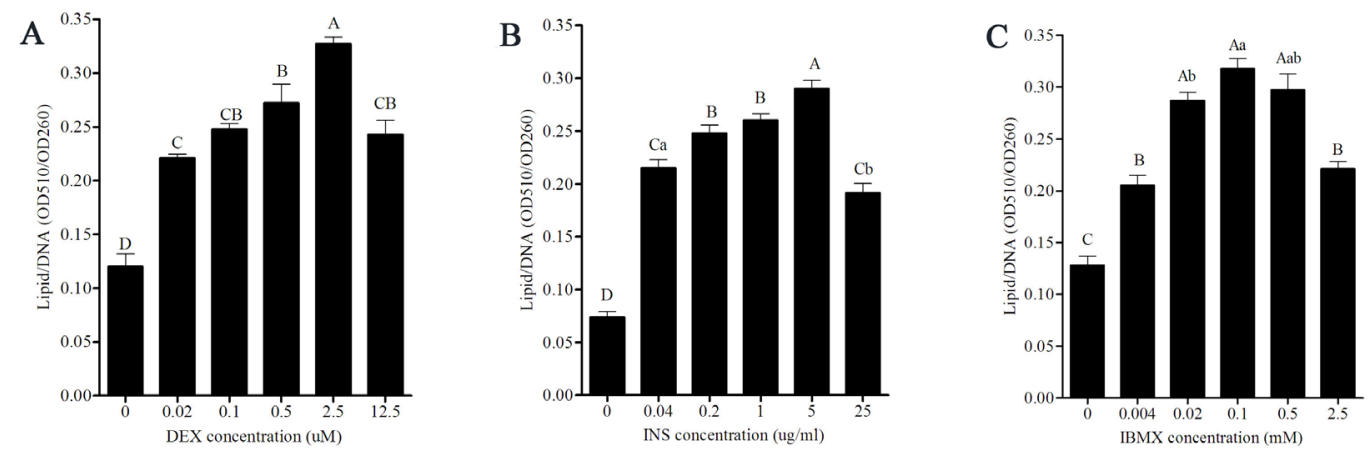

Figure 3. Influence of different DEX, INS, and IBMX on redifferentiation of dedifferentiation intramuscular adipocytes of the $3 \mathrm{rd}$ passage. A. Influence of DEX on redifferentiation. The progeny cells were induced in DMEM containing 10\% FBS, $5 \mathrm{ug} / \mathrm{mL}$ INS, and $0.5 \mathrm{mM}$ IBMX supplement with $0,0.02,0.1,0.5,2.5,12.5 \mathrm{uM}$ DEX, respectively. B. Influence of INS on redifferentiation. The progeny cells were induced in DMEM containing $10 \%$ FBS, $2.5 \mathrm{uM}$ DEX, and $0.5 \mathrm{mM}$ IBMX supplement with 0, 0.04, 0.2, 1, 5, $25 \mathrm{ug} / \mathrm{mL}$ INS, respectively. C. Influence of IBMX on redifferentiation. The progeny cells were induced in DMEM containing 10\% FBS, $2.5 \mathrm{uM} \mathrm{DEX}$, and $5 \mathrm{ug} / \mathrm{mL}$ INS supplement with $0,0.004,0.02,0.1,0.5,2.5 \mathrm{mM} \mathrm{IBMX}$, respectively. Averages with different letters are significantly different with lowercase $(\mathrm{P}<0.05)$ and majuscule $(\mathrm{P}<0.01)$.

In order to test whether differentiation was stable in intramuscular preadipocytes throughout long-term subculture, we compared the redifferentiation of progeny cells between the 3rd and 9th passages using the optimized concentrations of DEX, IBMX, and INS. Although progeny cells of both the 3rd and 9th passages can differentiate into lipid-laden adipocytes (Figure 4A), the redifferentiation ability of the 9th passage was significantly decreased compared to that of the $3 \mathrm{rd}$ passage $(\mathrm{P}<0.01)$ (Figure $4 \mathrm{~B})$.

A

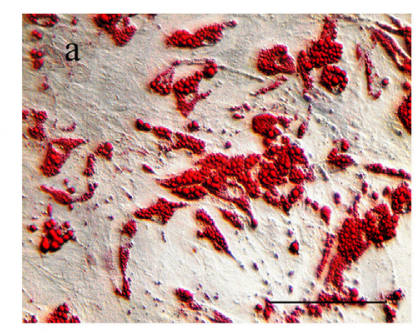

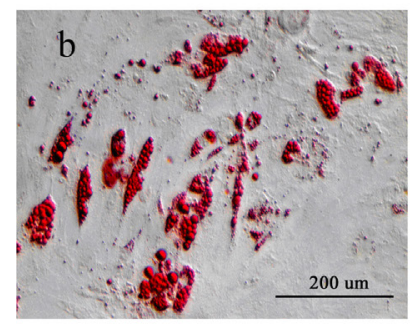

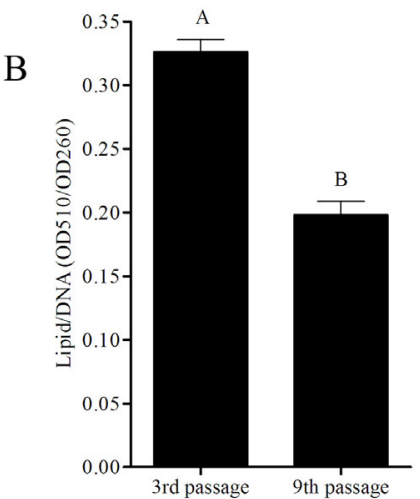

Figure 4. Redifferentiation capacity compared of dedifferentiation intramuscular adipocytes between the 3rd and 9th passage. A. Oil red O staining at the 9th day after induction. B. Comparison of cellular lipid accumulation at the 9th day after induction. Averages with different letters are significantly different $(\mathrm{P}<0.01)$. 


\section{DISCUSSION}

Intramuscular preadipocyte differentiation is most commonly investigated using SV cells (Grant et al., 2008a,b; Zhou et al., 2010). As SV cells consist of various cell types which may affect the differentiation of the preadipocyte (Ramsay et al., 1992), it is critical to obtain pure preadipocytes for this type of research. The isolation of intramuscular preadipocytes by means of adipocyte dedifferentiation has previously been demonstrated in mature pigs (Chen et al., 2010) but not in newborn piglets. In this study, we successfully separated the intramuscular adipocytes from the LD muscle of newborn piglets. The conditions of the collagenase process, centrifugation and filtration are all critical for obtaining mature adipocytes (Zhang et al., 2000; Tholpady et al., 2005; Justesen et al., 2004). Different quantities of type I collagenases $(0.075,0.1$, and $0.25 \%)$, centrifugation $(180,135$, and $186 \mathrm{~g})$, and nylon mesh $(250$ $\mu \mathrm{m}$ and $1000 \mu \mathrm{m}$ ) have previously been used in the isolation of mature adipocytes from fat tissue (Fernyhough et al., 2004; Tholpady et al., 2005; Matsumoto et al., 2008). In the present study, we found that $0.1 \%$ type I collagenase, $190 \mathrm{~g}$ centrifugation, and $300 \mu \mathrm{m}$ filtration can successfully isolate mature adipocytes from the LD muscle.

Mature adipocytes from newborn piglets can dedifferentiate into fibroblast-like progeny cells when cultured by ceiling culture. The process of dedifferentiation paralleled observations of previous studies using adult pigs (Chen et al., 2010). The redifferentiation ability of progeny cells was evaluated by morphological changes and marker gene expression. After induction, progeny cells started to accumulate lipid droplets in the cytoplasm. The cells became round at the 9th day of induction when small droplets merged with larger droplets, which were visualized by oil red $\mathrm{O}$ staining. The observed morphological changes of the progeny cells were similar to those of previous reports of preadipocytes (Taniguchi et al., 2008; Sung et al., 2010). PPAR $\gamma 2$ and $\mathrm{C} / \mathrm{EBP} \alpha$ act as the master switches for preadipocyte differentiation (Rosen and MacDougald, 2006) through a feed-forward circuit and regulate the expression of most adipogenesis genes (Alon, 2007). LPL is a rate-limiting enzyme of triglyceride accumulation (Ranganathan et al., 2006). Adiponectin is a hormone protein secreted by adipocytes (Ohashi et al., 2012). All of these genes showed higher expressions at the 9th day of induction $(\mathrm{P}<$ 0.01 ). Our results indicated that the progeny cells of dedifferentiated intramuscular fat cells can successfully redifferentiate into mature adipocytes when induced as normal. In other words, the progeny cells we obtained in this study could be used as the normal preadipocytes.

Additionally, the progeny cells maintained a fibroblast-like phenotype until induction and did not exhibit spontaneous differentiation. This is in contrast to results of a previous study in which the progeny cells from dedifferentiated adipocytes of adult pigs spontaneously redifferentiated into adipocytes without induction (Chen et al., 2010). This difference implies that the differentiation ability of dedifferentiated adipocytes may vary depending on the developmental stage of the animal.

In order to optimize the induction conditions, we chose the classic inducing reagents, DEX, INS, and IBMX. DEX binds to the cytosolic glucocorticoid receptor and then stimulates adipocyte differentiation with glucocorticoid response elements (Fernyhough et al., 2008). The glucocorticoid response elements drive CCAAT/enhancer binding protein $\delta$ expression, which can in turn activate the expression of peroxisome proliferator-activated receptor gamma (PPAR $\gamma$ ) (Rosen and Spiegelman, 2001). INS has a positive influence on adipocyte differentiation by enhancing lipid synthesis (Suryawan et al., 1997). IBMX increases the levels of intracellular 
cyclic AMP (cAMP) via inhibition of phosphodiesterase (Farmer, 2006). cAMP promotes PPAR $\gamma$ transcriptional activity (Kim et al., 2010) and can enhance adipocyte differentiation by exchanging proteins directly activated by the cAMP and protein kinase A signaling pathways (Petersen et al., 2008). In this study, we found that all three hormones had a positive influence on intramuscular adipocyte differentiation. Furthermore, we observed that optimal induction efficiency was achieved with $2.5 \mathrm{nM}$ DEX, $0.1 \mathrm{mM}$ IBMX, and $5 \mu \mathrm{g} / \mathrm{mL}$ INS.

Differentiation ability was reduced in the 9th passage relative to that of the 3rd passage. This result implied that the differentiation capacity of intramuscular preadipocytes decreases through time. Previous studies have also revealed that differentiation capacity will decrease, and even become lost altogether, in long-term cell cultures (Bruder et al., 1997; Banfi et al., 2000; Rombouts and Ploemacher, 2003). One of the possible reasons suggested for the decline in the differentiation capacity of mesenchymal stem cells to adipocytes is the inhibition of $\mathrm{H} 3 \mathrm{~K} 9$ acetylation in adipogenic promoters (Nobusue et al., 2008; Noer et al., 2009). However, the potential cause of the decline of differentiation capacity in intramuscular preadipocytes remains unknown.

In summary, in this study we successfully obtained intramuscular preadipocytes from newborn piglets using the ceiling culture method followed by adipocyte dedifferentiation. The intramuscular preadipocytes do not differentiate spontaneously and maintain fibroblast-like morphology until adipogenic induction. The intramuscular preadipocytes can redifferentiate into adipocytes and the redifferentiation ability reduced during subculture. The optimal induction conditions for intramuscular preadipocytes were determined to be $2.5 \mathrm{nM}$ DEX, $0.1 \mathrm{mM}$ IBMX, and $5 \mu \mathrm{g} / \mathrm{mL}$ INS. Therefore, this study created a new model for investigating the mechanisms of intramuscular adipocyte differentiation and metabolism in vitro.

\section{ACKNOWLEDGEMENTS}

Research supported by the National Natural Science Foundation of China (\#31272423) and the Fundamental Research Founds for the Central Universities (\#KYZ201113). We are also grateful to associate professor Huixia Li for help and support throughout this study.

\section{REFERENCES}

Alon U (2007). Network motifs: theory and experimental approaches. Nat. Rev. Genet. 8: 450-461.

Banfi A, Muraglia A, Dozin B, Mastrogiacomo M, et al. (2000). Proliferation kinetics and differentiation potential of ex vivo expanded human bone marrow stromal cells: Implications for their use in cell therapy. Exp. Hematol. 28: 707-715.

Bruder SP, Jaiswal N and Haynesworth SE (1997). Growth kinetics, self-renewal, and the osteogenic potential of purified human mesenchymal stem cells during extensive subcultivation and following cryopreservation. $J$. Cell. Biochem. 64: 278-294.

Chen J, Dodson MV and Jiang Z (2010). Cellular and molecular comparison of redifferentiation of intramuscular- and visceral-adipocyte derived progeny cells. Int. J. Biol. Sci. 6: 80-88.

DeVol DL, Bechtel PJ, Novakofski J, Carr TR, et al. (1988). Variation in composition and palatability traits and relationships between muscle characteristics and palatability in a random sample of pork carcasses. J. Anim. Sci. 66: 385-395.

Farmer SR (2006). Transcriptional control of adipocyte formation. Cell Metab. 4: 263-273.

Fernandez X, Monin G, Talmant A, Mourot J, et al. (1999). Influence of intramuscular fat content on the quality of pig meat - 1. Composition of the lipid fraction and sensory characteristics of m. longissimus lumborum. Meat Sci. 53: 59-65.

Fernyhough ME, Vierck JL, Hausman GJ, Mir PS, et al. (2004). Primary adipocyte culture: adipocyte purification methods 
may lead to a new understanding of adipose tissue growth and development. Cytotechnology 46: 163-172.

Fernyhough ME, Bucci LR, Hausman GJ, Antonio J, et al. (2005). Gaining a solid grip on adipogenesis. Tissue Cell. 37 : 335-338.

Fernyhough ME, Hausman GJ and Dodson MV (2008). Progeny from dedifferentiated bovine adipocytes display protracted adipogenesis. Cells Tissues Organs 188: 359-372.

Fortin A, Robertson WM and Tong AK (2005). The eating quality of Canadian pork and its relationship with intramuscular fat. Meat Sci. 69: 297-305.

Gerbens F, Jansen A, van Erp AJ, Harders F, et al. (1998). The adipocyte fatty acid-binding protein locus: characterization and association with intramuscular fat content in pigs. Mamm. Genome 9: 1022-1026.

Grant AC, Ortiz-Colon G, Doumit ME and Buskirk DD (2008a). Optimization of in vitro conditions for bovine subcutaneous and intramuscular preadipocyte differentiation. J. Anim. Sci. 86: 73-82

Grant AC, Ortiz-Colon G, Doumit ME, Tempelman RJ, et al. (2008b). Differentiation of bovine intramuscular and subcutaneous stromal-vascular cells exposed to dexamethasone and troglitazone. J. Anim. Sci. 86: 2531-2538.

Hausman GJ, Dodson MV, Ajuwon K, Azain M, et al. (2009). Board-invited review: the biology and regulation of preadipocytes and adipocytes in meat animals. J. Anim. Sci. 87: 1218-1246.

Justesen J, Pedersen SB, Stenderup K and Kassem M (2004). Subcutaneous adipocytes can differentiate into bone-forming cells in vitro and in vivo. Tissue Eng. 10: 381-391.

Kim SP, Ha JM, Yun SJ, Kim EK, et al. (2010). Transcriptional activation of peroxisome proliferator-activated receptorgamma requires activation of both protein kinase $\mathrm{A}$ and Akt during adipocyte differentiation. Biochem. Biophys. Res. Commun. 399: 55-59.

Lonergan SM, Stalder KJ, Huff-Lonergan E, Knight TJ, et al. (2007). Influence of lipid content on pork sensory quality within $\mathrm{pH}$ classification. J. Anim. Sci. 85: 1074-1079.

Matsumoto T, Kano K, Kondo D, Fukuda N, et al. (2008). Mature adipocyte-derived dedifferentiated fat cells exhibit multilineage potential. J. Cell. Physiol. 215: 210-222.

Nobusue H, Endo T and Kano K (2008). Establishment of a preadipocyte cell line derived from mature adipocytes of GFP transgenic mice and formation of adipose tissue. Cell Tissue Res. 332: 435-446.

Noer A, Lindeman LC and Collas P (2009). Histone H3 modifications associated with differentiation and long-term culture of mesenchymal adipose stem cells. Stem Cells Dev. 18: 725-736.

Ohashi K, Ouchi N and Matsuzawa Y (2012). Anti-inflammatory and anti-atherogenic properties of adiponectin. Biochimie 94: 2137-2142.

Petersen RK, Madsen L, Pedersen LM, Hallenborg P, et al. (2008). Cyclic AMP (cAMP)-mediated stimulation of adipocyte differentiation requires the synergistic action of Epac- and cAMP-dependent protein kinase-dependent processes. Mol. Cell. Biol. 28: 3804-3816.

Ramsay TG, Rao SV and Wolverton CK (1992). In vitro systems for the analysis of the development of adipose tissue in domestic animals. J. Nutr. 122: 806-817.

Ranganathan G, Unal R, Pokrovskaya I, Yao-Borengasser A, et al. (2006). The lipogenic enzymes DGAT1, FAS, and LPL in adipose tissue: effects of obesity, insulin resistance, and TZD treatment. J. Lipid Res. 47: 2444-2450.

Rombouts WJ and Ploemacher RE (2003). Primary murine MSC show highly efficient homing to the bone marrow but lose homing ability following culture. Leukemia 17: 160-170.

Rosen ED and Spiegelman BM (2001). PPARgamma : a nuclear regulator of metabolism, differentiation, and cell growth. J. Biol. Chem. 276: 37731-37734.

Rosen ED and MacDougald OA (2006). Adipocyte differentiation from the inside out. Nat. Rev. Mol. Cell. Biol. 7: 885896.

Sanosaka M, Minashima T, Suzuki K, Watanabe K, et al. (2008). A combination of octanoate and oleate promotes in vitro differentiation of porcine intramuscular adipocytes. Comp Biochem. Physiol. B Biochem. Mol. Biol. 149: 285-292.

Sugihara H, Yonemitsu N, Miyabara S and Yun K (1986). Primary cultures of unilocular fat cells: characteristics of growth in vitro and changes in differentiation properties. Differentiation 31: 42-49.

Sung HY, Kang SW, Kim JL, Li J, et al. (2010). Oleanolic acid reduces markers of differentiation in 3T3-L1 adipocytes. Nutr. Res. 30: 831-839.

Suryawan A, Swanson LV and Hu CY (1997). Insulin and hydrocortisone, but not triiodothyronine, are required for the differentiation of pig preadipocytes in primary culture. J. Anim. Sci. 75: 105-111.

Taniguchi M, Guan LL, Zhang B, Dodson MV, et al. (2008). Adipogenesis of bovine perimuscular preadipocytes. Biochem. Biophys. Res. Commun. 366: 54-59.

Tholpady SS, Aojanepong C, Llull R, Jeong JH, et al. (2005). The cellular plasticity of human adipocytes. Ann. Plast. Surg. 54: 651-656.

Webb EC and O'Neill HA (2008). The animal fat paradox and meat quality. Meat Sci. 80: 28-36. 
Wolins NE, Quaynor BK, Skinner JR, Tzekov A, et al. (2006). OP9 mouse stromal cells rapidly differentiate into adipocytes: characterization of a useful new model of adipogenesis. J. Lipid. Res. 47: 450-460.

Zhang HH, Kumar S, Barnett AH and Eggo MC (2000). Ceiling culture of mature human adipocytes: use in studies of adipocyte functions. J. Endocrinol. 164: 119-128.

Zhou G, Wang S, Wang Z, Zhu X, et al. (2010). Global comparison of gene expression profiles between intramuscular and subcutaneous adipocytes of neonatal landrace pig using microarray. Meat Sci. 86: 440-450. 